\title{
DE ARREGLOS PRODUCTIVOS LOCALES A ARREGLOS PRODUCTIVOS DE BASE COMUNITARIA
}

\author{
Luzia Neide Coriolano \\ Dra em Geografia, Coordenadora do Mestrado \\ em Turismo da UECE, Pesquisadora do CNPq
}

\section{Resumen}

Este ensayo problemátiza las reivindicaciones sociales y productivas frente al capitalismo, y las cuestiona sobre si las acciones comunitarias realmente son alternativas y no solo complementos del modelo hegemónico. En este contexto, entran las experiencias brasileñas sobre Arreglos Productivos Locales (APL), los que son analizados como políticas públicas a través de información secundaria, y de campo en el nordeste de Brasil. Se identifica que algunos APL son realmente comunitarios mientras que otros han sido impuestos con una lógica de arriba hacia bajo. Se profundiza sobre la relación entre turismo comunitario y economía solidaria, y sobre como las micro, pequeñas y medianas empresas se organizan para hacer frente a la competitividad global. Finalmente, se diferencia teóricamente a los conceptos de sociedad y comunidad, y como conclusión se considera que los esfuerzos comunitarios en los que participan organizaciones y personas locales son resistencias al capitalismo, por velar por la colectividad y el bienestar territorial a diferencia del individualismo que prevalece en las sociedades modernas.

Palabras clave: Arreglos Productivos Locales (APL), Capitalismo, Turismo Comunitario, Comunidad y Sociedad. 


\title{
FROM LOCAL PRODUCTIVE ARRANGEMENTS TO COMMUNITY-BASED PRODUCTIVE ARRANGEMENTS
}

\author{
Luzia Neide Coriolano \\ Dra em Geografia, Coordenadora do Mestrado \\ em Turismo da UECE, Pesquisadora do CNPq
}

\begin{abstract}
This essay problematizes the social and productive claims against capitalism, and questions them about if community actions really are alternatives and not just complements of the hegemonic model. In this context, brazilian experiences on Local Productive Arrangements (LPA) were analyzed as public policies through secondary and field information in northeastern of Brazil. It is identified that some LPAs are actually community experiences, but others others have been imposed with top-down logic. The relationship between community based tourism and solidarity economy is explored, and how micro, small and medium-sized enterprises are organized to facing global competitiveness. Finally, it differs theoretically to the concepts of society and community, and in conclusion it is considered that the community efforts involve organizations and local residents as a resistance to capitalism through collectivity and well - being in territory, unlike the individualism that prevails in modern societies.
\end{abstract}

Keywords: Local Productive Arrangements (LPA), Capitalism, Community Based Tourism, Community and Society. 


\section{Introducción}

Las dimensiones económicas y socio-espaciales del turismo son enfoques que impulsan varias preguntas: ¿Cómo economías pequeñas se insertan y conquistan espacios en la economía global? ¿Qué motivos, además de los mercadotécnicos, son inherentes a emprendimientos solidarios? ¿Por qué las formas alternativas de organizaciones productivas se refieren a las comunidades y el desarrollo local? ¿Cómo los arreglos productivos locales ${ }^{1}$ se relacionan con el turismo? ¿Y cómo pueden ser solidarios?

La ocurrencia de procesos de desarrollo local en las diferentes regiones del mundo, desde finales de 1970, viene despertando una creciente atención de los gobiernos, entidades e investigadores que piensan un modelo de desarrollo capaz de responder a los desafíos provocados por los cambios radicales, en los modos de producción, organización y gestión de empresas en los espacios de actividad. La intensificación del comercio mundial, con consecuente internacionalización de la producción y una mayor interdependencia entre la producción de bienes y servicios propiciados por el avance de las tecnologías del transporte, comunicación e información, junto con la creciente apertura de las economías nacionales, ha puesto desafíos a las distintas regiones del mundo, especialmente a las con poca posibilidad de adaptarse rápidamente la estructura económica a los nuevos parámetros de competitividad, como el Noreste brasileño, ahora mucho más amplio y cambiante.

Bajo la nueva norma pós-fordista, son los lugares más flexibles, fluidos, más capaces de recibir, comprender y llevar a cabo los cambios, que surgen enfrente. A veces, los más aptos para los desafíos no siempre son actores sociales vinculados a empresas prodigiosas o economías establecidas y sus estrafalarias técnicas mercadológicas. Son pequeñas y medianas empresas o empresarios locales que, llamados a responder satisfactoriamente el despotismo del mercado, se debaten buscando estrategias localizadas de resistencia y supervivencia.

En este sentido, el local se ha consagrado y ganado papel activo en la organización de estrategias de supervivencia, al capitalismo contemporáneo. El proceso de especialización de la producción termina por fragmentarla, desplazando la fabricación de ciertos artículos para donde ella es más ventajosa. Se incrementa, por lo tanto, la necesidad del intercambio y la circulación asume importancia crucial y amplía las posibilidades de producción. Pronto, más y más lugares son selectivamente incorporados en las corrientes globales.

$\overline{1}$ Conocidos también como Acuerdos Productivos Locales (APL). 
En el período de mayor afirmación (1945-1975), el capitalismo perpetúa ideas y valores que sustentaron paradigma de desarrollo fuertemente vinculado a la centralidad de la economía y la reducción de todo a la simple producción de bienes y progreso técnico (PIB, índices de la bolsa, control de divisas, ingresos per cápita, etc.) desvalorizando cualquier lazo de humanidad. La re definición del concepto, sin embargo, ahora impregna otras esferas que no la puramente económica. Dice Sachs (2006) que situaciones que tuvieron lugar en el siglo XX no van a servir como modelo para el nuevo milenio y que nos obligará a salir del reduccionismo económico, incorporando también el social, cultural y ambiental, que ya no pueden ser más ignorados.

Fue precisamente la necesidad de pensar maneras de inserción productiva, en lugares con grandes diferencias sociales, en un mundo globalizado, económicamente excluido y socialmente perverso, que hizo volver a la escala regional y local. La reconstrucción de lo regional y de lo local, trajo la idea de que cualquier intervención que anhele mejora cualitativa en la forma de vida de las personas debe partir del modelo endógeno de desarrollo, capaz de promover cambio estructural y buscar eficiencia en la producción, uso racional de los recursos naturales y distribución más equitativa del empleo e ingreso. Sin embargo, si el desarrollo regional (y local) se presenta como algo nuevo, siendo una nueva escala de intervención, es necesario pensar en las ideas y sobre todo en las palabras que lo definen. Por lo tanto, la explicación clara y coherente de los términos y conceptos es necesaria, sin la cual llega al vacío, la ambigüedad, o, peor aún, la pérdida de significado del término. Y saber dar nombre a las cosas es, ante todo, práctica emancipadora.

Sin duda, el crecimiento económico, capacidad de exportación y progreso técnico no pueden traducir del todo al significado del concepto de desarrollo. En este sentido, el sociólogo Francisco de Oliveira (2001) ayuda en este esfuerzo de reflexión. En la tarea de pensar el significado del desarrollo, este pensador de la realidad brasileña se pregunta hasta qué punto el discurso del desarrollo endógeno, con base local, o cualquier otro término en este sentido se muestran como una abstracción, o mera adaptación al contexto económico-mundial actual. A diferencia de lo que podría ser una revolución ante una realidad palpable que se contrapone como un paradigma alternativo a la orden económica vigente y a las designaciones globales. Es este modelo la contrapartida a los desequilibrios y distorsiones estructurales del capitalismo, expresión local de resistencia o simplemente un truco milagroso de escamoteo de los conflictos sociales enraizados en los distintos agentes que conforman el espacio y sus sin fin de intereses subyacentes, ¿adaptando e igualando a todos en el mismo plano? Delante de la provocación, se puede entonces considerar ¿Cómo el desarrollo regional y local se presenta y en que se contraponen al movimiento perverso de la economía globalizada? 
En la lógica de Oliveira, se llega al desarrollo que tiene por obligación dar cuenta de la complejidad de los actores hegemónicos y hegemonizados en la batalla diaria, permitiendo prácticas sociales y espaciales capaces de recuperar la dimensión humana, superar problemas y ampliar oportunidades de intervención y elección de los individuos y de la colectividad. Podría así el desarrollo regional y local crear locus interactivos de ciudadanos, recuperando la iniciativa y la autonomía en la gestión del bien común, poniendo el gobierno al alcance de los ciudadanos. Todavía, para que este desarrollo se produzca al menos tres dimensiones deben ser consideradas:

- La capacidad efectiva de participación de la ciudadanía, lo que se puede llamar "gobierno local", que aparece como rescate del poder local en medio a la crisis de la democracia representativa que separa gobernantes y gobernados. La promoción del desarrollo requiere la participación efectiva del sector público y de la voluntad política de los gobiernos locales que, a pesar de las limitaciones, juegan papeles clave en el proceso. Hay poca relación entre el ciudadano y lo propuesto, separación ventajosa para los políticos y los grandes grupos económicos que constituyen una verdadera oligarquía, pero totalmente perjudicial y debilitante para el ciudadano común sometiéndolo a la situación de inferioridad permanente;

- La posibilidad de un desarrollo local es actuar corrigiendo la tendencia de concentración inherentes al proceso capitalista a nivel macro. Todavía el avance tecnológico aleja tal posibilidad, sometiendo de hecho, cada vez más, el local a la lógica global. En este sentido el lugar se convierte diferente al residente, pues sometido a otro espacio lejano, modifica su uso no solo específicamente de acuerdo al lugar.

- $\quad$ El desarrollo regional y local instala su propia lógica para recuperar el poder constituyente del pueblo, por la creación de instituciones no necesariamente contrarias a las existentes, pero no tan sumisas a ellos. Esto abre espacios para nuevas iniciativas, capaces de subvertir el orden impuesto o recrear el orden por la experiencia social y política.

En esta perspectiva, surgen estrategias que pueden contribuir realmente a la mejora del modelo de civilización, no en los moldes capitalistas excluyentes y camufladores de conflictos, pero como posibilidad de superación y re diseño de otra globalización. Emergen, en diversos lugares, experiencias calcadas en el conocimiento y el hacer local que dislocan, para escala regional y local, la responsabilidad por el desarrollo. El contexto de la globalización requiere un alto nivel de competitividad, no sólo de las empresas con sus productos y ambiente relacional, pero de la totalidad del sistema económico e institucional (Casarotto y Pires, 1999). La necesidad de logro de ventajas competitivas 
que permitan la expansión de mercados y la defensa a exposiciones determinadas por la apertura del mercado, requiere de acciones descentralizadas de empresas e instituciones públicas, implicando fuerte complicidad entre ellos, en la relación basada en la cooperación, sinergia, complementariedad y aprendizaje garantizando, en el mismo tiempo, adaptación, agilidad y flexibilidad (Amaral Filho, 2004).

En este sentido, las acciones de varios actores hegemónicos se dirigen, cada vez más, para la creación de políticas que aproximan y movilizan acciones de mercado con intervención del gobierno, involucrando específicamente economías locales y regionales, re definido el papel del poder público y buscando nuevo paradigma de desarrollo. Se acepta la idea de que estrechas relaciones entre actores locales, desarrollan función determinante en la competitividad de las actividades económicas (Benko, 2001). Por lo tanto, toda la mística del desarrollo gravitar actualmente en torno del concepto de competitividad sistémica y promoción económica local, abriendo camino para endogenización del desarrollo llevado a cabo por el poder público y empresas privadas, con políticas activas de construcción social del mercado, dice Benko (2002, p. 57).

Desde el punto de vista histórico-económico, el punto inicial de la nueva estrategia surge en la década de 1970, con experiencias de desarrollo local, como alternativa a las formas organización clásica. El pionerismo del sur de Italia (Tercera Italia) abre posibilidades de reproducción en varias partes del mundo. Apoyando aglomeraciones territoriales de pequeñas empresas organizadas en régimen de especialización flexible, la experiencia italiana proporcionó una intrincada relación en red sobre competencia y cooperación, impulsada por la innovación continua y por la fabricación de productos de alta complejidad, configurando el ambiente que abría oportunidad de superación del bajo desarrollo que históricamente acometía esta región (Piore y Sabel, 1984).

Los aglomerados productivos son apoyados por instituciones que proporcionan recursos humanos, recursos financieros e infraestructura. Adviene de la interacción entre empresas e instituciones que apoyan la innovación y conocimiento de experiencia. De un modo general, los conceptos de distrito industrial, clusters, sistema productivo local y arreglo productivo local representan aglomerados de actividades productivas, especialmente concentradas, con gran afinidad económica, desarrolladas por empresas autónomas de micro, pequeño, mediano y grande porte, intensamente articuladas, formando ambiente de negocios donde prevalecen relaciones de recíproca confianza entre las distintas partes implicadas (Porter, 1993).

Algunos autores creen que los Arreglos Productivos Locales - APLs no pueden ser prefabricados o creados, sin embargo, subrayan que el sector público y las instituciones colectivas juegan un papel clave en la identificación y en el incentivo al fortalecimiento. 
La identificación del Arreglo Productivo Local - APL está directamente relacionada a la capacidad de percepción, en varios lugares, de la base cultural y social común que, uniendo agentes económicos a través de comportamientos, valores, normas y prácticas cotidianas, potencialice la formación del clima organizacional local dirigido para mejorar las condiciones del grupo o comunidad. Amorim (1998, p.44), estudiando arreglos de producción en clusters, señala que prácticas de cooperación son más fácilmente observadas en ambientes donde los integrantes tienen alguna afinidad, es decir, comparten mínimamente la historia común. Factores objetivos y subjetivos, asociación, cooperación, imagen positiva, clima económico favorable, competencia del gobierno, descentralización decisoria y otros se convierten decisivos en la conformación del sistema de relaciones humanas territorializadas (capital intangible), capaz de instalar un círculo virtuoso que traerá consigo innovación, diversificación y enriquecimiento de las actividades del medio.

Los Arreglos Productivos Locales de Ceará son respuestas locales, derivados de factores históricos que concentran, en un mismo territorio, micro y pequeñas empresas de subsistencia (sector informal), a veces, familiares, con la competencia técnica baja, comercial y gestión que, por regla general, producen esencialmente los mismos productos. En este particular, cuentan con un capital social modesto, ambiente de desconfianza, competencia contraproducente y mínima capacidad innovadoras con limitaciones competitivas locales. Gran parte de los APLs de Ceará es construida en base de la actitud empresarial de individuos, no siempre calificado. Las personas, en la ausencia de ocupación en el mercado laboral formal - en especial en las zonas rurales - establecen micro empresas como alternativa al desempleo, lo que conduce, de hecho, en una de las características de la organización productiva local en países periféricos.

El turismo, como actividad intersectorial, muy articulada e integrada con los otros sectores económicos, sociales y culturales (Coriolano, 2003b), mientras que tiene un gran potencial de agregación a los APLs - especialmente los relacionados con artesanías y productos regionales - requiere de la confluencia de acciones precisas y de gran escala para articular diferentes actores que conforman el trade turístico. Y esto no es tarea fácil, porque el turismo no puede ser pensado de forma aislada. Característico de la sociedad de consumo, el turismo envuelve un conjunto de determinados beneficios capaces de atraer ciertos grupos de consumidores en busca de satisfacción, de motivaciones y expectativas (Droulers y Milani, 2002).

Particularmente, en Ceará, la masificación concentrada de destinos costeros, la afluencia cada vez mayor de capital extranjero y relativo amateurismo de ciertos servicios obstaculizan el avance de la actividad y también revelan la diversidad de intereses y estrategias detrás de cada empresario del turismo. Además, el propio poder público 
ha sido incapaz de dar cuenta de la diversidad, dando prioridad a los mega proyectos que llegan a segmentos específicos, en detrimento de otros flancos, pero no por eso, de menos importancia social. Por otro lado, la propia manera de ver el turismo, a menudo, como una actividad redentora de todos los males del bajo desarrollo, capaz de garantizar un futuro de riqueza y prosperidad a todos los que se atreven a llevarla a cabo, conduce al fracaso de algunos empresarios, a veces, contraproducente a la actividad. Por otra parte, la frugalidad de algunos destinos y descaracterización socio-espacial lo torna incapaz de desarrollar la sinergia necesaria para la realización, o incluso, la misma identificación del APL del turismo.

El turismo, sin embargo, puede implicar el paradigma del desarrollo endógeno, en la medida en que moviliza sus propios recursos o fuerzas socio económicas, institucionales y culturales locales, protagonizada por los actores locales, es decir, un gran número de emprendedores de micro, pequeñas y medianas empresas locales, ramificadas por diversos sectores y subsectores, centrándose en las necesidades propias de las comunidades (Cavaco, 1996). Otra gran ventaja, de acuerdo con Amaral et all (2004), es la posibilidad de transformar "factores dados" en "factores dinámicos" reduciendo, en gran medida, los costos de la creación e implementación que envuelven cualquier proyecto nuevo de desarrollo.

Por lo tanto, la percepción de aglomeraciones de micro y pequeñas empresas de diversos sectores, con fuertes vinculación al turismo no parece tarea difícil. Sin embargo, a partir de entonces, consolidar acciones, en el sentido de dar forma al APL no se muestra tarea tan fácil. Todavía algo puede ser hecho, en el sentido de potencializar los centros y arreglos productivos. En Fortaleza, la Región Metropolitana y en las comunidades costeras, ya se tiene experiencias que van en esta perspectiva. Es el caso de tiendas de entrega inmediata de artículos de cuero, en el barrio de Parquelandia, formando un grupo de emprendimientos que, en la última década, fue constituido como un circuito alternativo al Mercado Central (venta de artesanías), e incluso, la agrupación de la Av. Monsenhor Tabosa, también con un gran potencial para conformarse como APL, a pesar de la dificultad de reunir un número elevado y difusión de micro, pequeñas y medianas empresas.

Por lo tanto, la percepción de aglomeraciones de micro y pequeñas empresas de diversos sectores, con fuertes vinculación al turismo no parece tarea difícil. Sin embargo, a partir de entonces, consolidar acciones, en el sentido de dar forma al APL no se muestra tarea tan fácil. Todavía algo puede ser hecho, en el sentido de potencializar los centros y arreglos productivos. En Fortaleza, la Región Metropolitana y en las comunidades costeras, ya se tiene experiencias que van en esta perspectiva. Es el caso de tiendas de entrega inmediata de artículos de cuero, en el barrio de Parquelandia, formando un grupo de emprendimientos que, en la última década, fue constituido como un circuito alternativo 
al Mercado Central (venta de artesanías), e incluso, la agrupación de la Av. Monsenhor Tabosa, también con un gran potencial para conformarse como APL, a pesar de la dificultad de reunir un número elevado y difusión de micro, pequeñas y medianas empresas. A pesar del sugerente título, es necesario desmitificar la idea de que se puede habilitar alguien como emprendedor en lo que quiera que sea; la iniciativa empresarial se ha convertido en jerga. De hecho, la capacidad emprendedora de las personas no se une directamente a un conjunto de conocimientos de aprehensión rápida, por lo tanto. No hay manuales ni recetas prontas de cómo convertirse en emprendedor (Dolabela, 2006). La capacidad es intangible, no es de naturaleza universal, no es transferible, es peculiar sólo para el poseedor. Y no se identifica como talento nato, manifiesto individualmente con que algunos son bendecidos y otros no lo son. Pero como fenómeno cultural, de experiencias que extienden y califican las elecciones de los individuos, crea posibilidades de desarrollo de atributos sociocomportamental que dan aliento para pensar, soñar, crear y la voluntad de modificar, cambiar, de atreverse a enfrentar la situación. Todo esto reforzado y perpetuado en el tiempo, dentro de una determinada sociedad o grupo, en un país, ciudad, barrio o comunidad.

El comportamiento emprendedor se desarrolla y se hace popular en actitudes que enseñan a lidiar con el riesgo, aprender de ella, a pensar más allá, a tener autoestima, valor, confianza y capacidad para gestionar la propia vida, viendo, en el cambio, la oportunidad y no la amenaza. Pasa, necesariamente, por la valorización y capacitación para la asociación, la cooperación, colaborando para la realización personal y profesional, de la persona sin desconsiderar el colectivo. Pero, ¿Cómo ser un emprendedor en un país como Brasil y sobre todo en el Noreste?

Brasil tiene un enorme potencial emprendedor en relación con otros países. Todavía el sentido de la supervivencia y no de oportunidad de mercado ha llevado a muchos al emprendimiento. Por lo tanto, hay que distinguir el emprendedor por necesidad y por oportunidad. La esencia del emprendedor está en la percepción y en el aprovechamiento de nuevas oportunidades, en el ámbito de los negocios "[...] siempre tiene que ver con la creación de una nueva forma de uso de los recursos nacionales, en que ellos sean desplazados de sus empleos tradicionales y sujetos a nuevas combinaciones "(Schumpeter apud Fillion, 1999, p. 7). La dinámica económica brasileña ha ocasionado inevitable declinación en los niveles de empleo, con repercusión, en el caso brasileño, en el aumento de la economía informal. Esto ha empujado a millones de brasileños a emprender, mismo que objetivamente no garantiza el éxito, por lo contrario, ha dado lugar a consecuencias desastrosas y minado las nuevas iniciativas, y, lo que es peor, la cultura empresarial desanimada. Sin embargo, no siendo la opción redentora del desempleo, el emprendimiento no puede y no debe pasarse por alto como una alternativa real (RICA, 2004). Por lo tanto, las iniciativas emprendedoras deben ser mejor captadas, valoradas y alentadas por el poder público, lo que va más allá de la retórica de la política electoral. 
Ser emprendedor es, ante todo, trabajar con rupturas y con universo temporal impredecible, porque el emprendedor se enfrenta con inercia, resistencia, resiliencia, que viene de las creencias y los valores individuales reafirmados en formas de pensar y actuar de la persona o institución. Frente a esto requiere por supuesto una buena dosis de paciencia, perseverancia y creatividad. Es posible sí y también importante, la propiedad de las metodologías de desarrollo del emprendimiento (producción, planificación y poder) y conocimiento instrumental (flujo de caja, diagnóstico de mercado, análisis financiero, plan de negocios, plan de marketing, gestión estratégica, etc.), puesta al servicio del espíritu emprendedor y tan bien difundidos por instituciones renombradas como SEBRAE / EMPRETEC y el SENAC. Sin embargo, el filósofo español Ortega y Gasset (1973) nos recuerda que el mundo es el individuo y sus posibilidades. Los caminos, por lo tanto, no se dan, pero si son descubiertos y adaptados por el emprendedor y en cada lugar. La región no es algo firme, inmutable, es un campo de infinitas posibilidades, que se compone de un sinfín de ideas y actores.

Los modelos de desarrollo local, basados en APLs, no cubren la enorme deuda social acumulada a lo largo de la historia de Brasil, aumentada por el ajuste macroeconómico neoliberal en la década de 1990, ni tampoco, reemplaza las tradicionales políticas industriales de desarrollo de la posguerra. La experiencia de organización de aglomerados productivos, fácilmente adoptada por el Gobierno de Ceará, como referencia de integración entre lo económico y lo social, debe ser aprehendida con énfasis en determinación de lo más universal, que apunta a la dimensión ciudadana del nuevo modelo de desarrollo, debiendo valerse de prioridades, medidas, instrumentos y procedimientos capaces de inducir y alentar la participación y el compromiso del poder público, de las empresas y de las organizaciones de la sociedad civil, para la construcción de proyectos concretos de la ciudadanía general. Y el turismo puede captar esta dimensión, ya que hay una subutilización del potencial de la actividad en la metrópoli y en el interior del Estado, revelando el bajo nivel de organización de la actividad fuera del circuito concentrado por la demanda turística. En este sentido, se vuelve a la pregunta: ¿Puede la región y el territorio local responder con eficacia a los desafíos planteados por el bajo desarrollo económico y social del Estado? ¿Qué llevó a los arreglos productivos locales a unirse con el predicado de política social?

A pesar del éxito del modelo, en algunos estados, es pronto para hacer cualquier análisis definitivo sobre las experiencias brasileñas. Nuestras peculiaridades políticoeconómica, social y territorial no garantizan la simple transposición de experiencias, siendo precipitado considerarlas no cualificadas. Es cierto que las formaciones de acuerdos formales se muestran más vigorosos en la región centro-sur del país, en torno a los textiles, calzados, muebles, metales, en comparación con la región de Noreste. Porlotanto, los arreglos productivos locales sehan extendidoportodoelpaís, comounamoda, y la solución para pequeños lugares, lo que merece una reflexión, análisis y evaluación. Las 
experiencias exitosas se dan a conocer en la contribución a la elaboración de regulaciones y posturas normativas, como una forma de desarrollo socio económico de los pequeños lugares, como si las experiencias exitosas podrían reproducirse. Se sabe que el potencial regional y local, así como la cultura, formación, compromiso y la voluntad política de los residentes locales, y otros factores, envuelven políticas de desarrollo, diferente de un lugar a otro, evitando la generalización. Muchos arreglos se han hecho desde arriba hacia abajo, como otra forma de reorganización del modelo industrial o de la economía de mercado.

Por otra parte, la falta de conceptualización precisa de Arreglo Productivo Local, porque lo que define arreglo o acuerdo sirve para definir cualquier otro proyecto económico del gobierno, así como la falta de objetividad de estrategias y método específico de análisis acaban por hacer inviable las respuestas esperadas de los acuerdos. Los economistas como, por ejemplo, Crocco (2003) Benevides (1997) admiten que existe una visión romántica de los APLs y del desarrollo local, ya que son considerados como si no existieran clases sociales, diferencias, conflictos y luchas. También es necesario preguntarse acerca de las posibilidades y el alcance de las economías locales, frente a la globalización. Los economistas dicen que los acuerdos de producción "no hacen las leyes del mercado" las que dominan el consumo mundial y tienen una debilidad importante.

Los acuerdos de producción hacen hincapié en el espíritu empresarial y en la competitividad, siendo que rara vez se discuten las condiciones para que la generación de conocimiento se convierta intrínseco al lugar y torne a la gente capaz de convertir el modelo de desarrollo del país, cuestionando las leyes del mercado y así como superar la omisión de los Estados cuanto a las políticas sociales. Las preguntas requieren por lo menos que se reflexione más acerca de las políticas de los Arreglos Productivos Locales, así como sobre el desarrollo regional y local. Cabe preguntarse ¿Estos son ajustes del modelo, o son una forma de hacer frente al modelo económico y van más allá de la economía solamente? O ¿Pueden socavar la economía neoliberal y demostrar una sociedad más humana y más solidaria?

Se encuentran acuerdos productivos reconocidos como economías alternativas, informales, solidarias que dependen del nivel de organización de pequeñas comunidades, barrios o grupos y son estrategias de supervivencia que encuentran, en la actividad turística articulada con muchas otras, espacios para expansión. Son conocidos en Ceará, como Arreglos Productivos Locales de Base Comunitaria, auto-designación, por partir de comunidades, por botar el enfoque de la acumulación y centrarse en la gente, la cultura y la protección del ambiental, con motivaciones no puramente económicas. Asumen la formación de un núcleo cuyo sentido de evolución se vuelve una forma de organización capaz de articular los elementos productivos de una comunidad. 
Por lo que algunos centros productivos no se caracterizan, en efecto, como APLs, pero tienen otra manera de producir, y algunos son formas de resistencia a la acumulación capitalista. Están colocados, sobre todo en los polos receptores de turismo, destacándose: centros de pescadores, pousadeiras, bugueiros, artesanas, algueiras, tapioqueiras, vendedores ambulantes, experiencias de economía solidaria o economía de comunión en muchas comunidades, centros culturales, entre otras formas de asociación y organización para producir incluyéndose en la cadena productiva del turismo. Las actividades no son sólo económicas, sino también son oportunidades de experimentación y reflexión sobre la lógica capitalista global y maneras de hacer frente en experiencias contra hegemónicas. Es decir, desde lo local, elaborar un modelo de sociedad más justa y solidaria que se pueda convertir en propuesta al estado-nación brasileño. Como decía Milton Santos (2002c, p. 147), una propuesta de transformación nacional ciertamente no partirá de los ricos y poderosos, pero de los pequeñas y de los suburbios que desean una globalización más inclusiva. Otra globalización implica un cambio radical de las condiciones actuales, de modo que la centralidad de las acciones sea centrada en el hombre y no en el capital.

\section{Comunidad en la sociedad moderna contemporánea}

En el mundo antiguo se destacaban formaciones de pequeños grupos sociales que vivían estrechos lazos de amistad y dependencia, llamados comunidades, como una forma de hacer frente a las duras condiciones de vida. Era la vida en comunidad que contribuía para el individuo encontrar respuestas necesarias a los problemas individuales y colectivos, con la ayuda del grupo. Con el desarrollo de la vida moderna y con el aumento de la población se fue perdiendo el sentido de comunidad y de sociedad, otra forma de organización social, basada en el Estado, en las instituciones, en el control social, en el individualismo, con dominio de tecnología, de normas y de la cultura de masa. En el mundo moderno, la instalación de la sociedad industrial causó gran impacto al modo de vida rural y solidaridad. Dice Bauman (2003, p.33) que "el capitalismo moderno", en la expresión de Marx y Engels, "derrite todos los sólidos", y las comunidades con auto-sostenimiento y auto-reproductivas "aparecen en un lugar de destaque en el rol de los sólidos licuados".

Comunidad viene de la palabra común y significaba que la tierra y los recursos existentes en los lugares podían ser disfrutados por todos, de acuerdo con las necesidades de cada uno. En el convivir comunitario primitivo todo era común a todos, no existía la propiedad privada, la apropiación era para suprimir todas las necesidades y todos asumían responsabilidades. La organización en forma societaria, persigue el mismo objetivo de que todas las personas sean iguales y libres, ocurren diferentes maneras de entender y practicar esta idea. Se produjo un modelo de sociedad que se dirige a la acumulación y no satisface las necesidades de todos, donde se vive aglomerado de personas siendo, por lo tanto, este modelo de sociedad cuestionada por muchos. En contra punto, pequeñas ciudades 
con baja densidad de población, resisten a cambios, hacen volver la idea de comunidad.

En la antigua Grecia, el oikos nomos indicaba la "administración de la casa" y la casa significaba familia y comunidad. Ander-Egg (1980, p.45) dice que comunidades:

Un agrupamiento organizado de personas que se perciben como unidad social, participan de los mismos intereses, objetivos y funciones comunes, con conciencia de pertenencia, situados en una determinada área geográfica, en la cual la pluralidad de personas que interactúan más intensamente entre sí, que en otro contexto.

Subyacente a este concepto esta la idea de lugar que permite la proximidad geográfica con intereses comunes. Pasamos de un mundo donde predominaban las comunidades para donde predomina simplemente la sociedad. Dice Max-Neef (2005, p.13) que:

[...] de la comunidad como elemento dominante, a la constitución de la sociedad hay un cambio humano de gran importancia. El estilo económico dominante, en su versión neoliberal estimula y fortalece no la individualidad, sino el individualismo, y en consecuencia la destrucción de la comunidad.

La comunidad en la opinión de Claval (2007, p.114) sirve de modelo:

[...] a una serie de unidades sociales y culturales por ser un pequeño grupo coherente, donde los miembros están vinculados por relación de confianza mutua, poder multiplicarse por la emigración o extenderse para englobar un gran número de personas vinculadas por ciertos trazos fundamentales de la cultura.

Explicando comunidad, Diegues (2002, p.83) muestra el padrón tradicional como criterio importante para definición de culturas o población, además del modo de vida. Este autor explica que las "culturas tradicionales"

[...] están asociadas a modos de producción pre-capitalistas, propios de sociedades en que el trabajo todavía no se ha convertido en mercancías, donde hay gran dependencia del mercado ya existente, pero no es total. Estas sociedades desarrollaron formas particulares de gestión de los recursos naturales que no miran directamente el lucro, pero si la reproducción social y cultural, así como las percepciones y representaciones con relación al mundo natural marcadas por la idea de asociación con la naturaleza y dependencia de los ciclos. 
La transformación de comunidad a sociedad provocó alteraciones en el mismo hombre que fue desaprendiendo a ser solidario y fraterno. Se pasó a tener apenas conocidos (desconocidos aún mejor) cuando mucho socios y competidores. La vida en sociedad eligió otros valores, ya que es guiada por principios capitalistas y burgueses. Por lo tanto, hablar de comunidad en la modernidad significa ir en la contramano del modelo de la sociedad puesta: individualista, segregada, injusta, centrada en los valores del capital o del consumo. La idea de comunidad, el compartir fraterno ha llevado a algunos a huir de ella, dice Bauman (2003) "este trazo por si solo hace del "comunitarismo" una filosofía de los débiles, y estos no pueden ejercer la individualidad. Para los poderosos y exitosos el deseo de dignidad, mérito y honra, paradójicamente exige negación de la comunidad". El individualismo lleva a creer que el crecimiento personal es un acto individual, resultado de esfuerzos de cada uno y la competitividad lleva a no querer contribuir con el crecimiento de los demás.

Compartir, según el enfoque burgués, es confundido con el asistencialismo, a diferencia de las teorías críticas que la entienden como justicia social. Existe, pues, un dar contaminado por el deseo de poder sobre el otro, que busca la dominación e incluso la opresión de las personas y los pueblos. Es compartir solo en apariencia. Hay, sin embargo, proceso solidario que busca la satisfacción y el placer del propio acto de compartir, de expresión egoísta, y, en general, es percibida por el receptor como humillación u ofensa. Existe un dar utilitario, interesado, presente en ciertas tendencias actuales del neoliberalismo, de los políticos, que básicamente busca su propio beneficio, lucro. Por lo tanto, este dar no crea mentalidad nueva, no contribuye a la transformación del modelo económico. Existe, por último, el compartir que se abre al otro, individuo o pueblo, que es respetando su dignidad, sus costumbres, su cultura y tradición. Así es que Araújo $(1998$, p. 20) y la autora creen en el compartir. La cultura del donar - la filosofía de la economía social, la economía de comunión - se ajusta con las políticas de participación deseadas por las comunidades.

Cuanto a la emergencia de las comunidades, debemos preguntarnos acerca de las circunstancias a las cuales resurgieron las comunidades de forma tan contundente en un mundo globalizado ¿Pensar en comunidad significa un retroceso o la búsqueda de nuevos caminos? No hay procesos totalmente continuos, ellos ocurren por continuidad y discontinuidad. Por lo tanto, las comunidades, en la sociedad moderna, significan una crítica a la forma de vida con profundas desigualdades sociales, colocando la libertad y la igualdad en el plano metafísico. En la sociedad moderna, la comunidad expresa una organización colectiva de reivindicaciones por la búsqueda de mejores condiciones de vida, de la lucha para sociedad pautada en la justicia y en la igualdad de derechos. La vida en comunidad requiere igualdad para que la libertad pueda ser realizada. Aunque el concepto de comunidad haya sido cooptado con otros significados y se hable de ella con diferentes intereses, bastante distanciados de su verdadero significado, aún se puede encontrar auténticas comunidades. Se creó una 
verdadera paradoja: las comunidades se vuelven dispensables, pero cada vez más se clama y se pide por ellas, con insistencia. Por lo tanto, dice Bauman (2003, p.60):

Esto no quiere decir que "comunidad" este ausente en el vocabulario de la élite mundial, ni que, sea mencionada, sea negada, y censurada. Es sólo que la comunidad de la Lebenswelt de la élite mundial es muy diferente de aquella otra "comunidad" de los débiles y desposeídos. En cada uno de los dos idiomas en que aparece, las dos elites globales y la de los dejados para atrás, la noción de "comunidad" corresponde a experiencias totalmente diferentes y con aspiraciones opuestas.

Muestra Ferdinad Tönnies (apud Bauman, 2003, p.15) que la distinción entre comunidad antigua y sociedad moderna es que en la primera existe comprensión compartida de todos los miembros, "no un consenso, porque este es producto de negociación, conflicto, molestia y golpes ocasionales". El entendimiento comunitario no necesita ser buscado, ni mucho menos construido, ya está ahí, para ser utilizado, por lo que los miembros de una comunidad se llevan muy bien y esta comprensión "precede a todos los acuerdos y desacuerdos", dicen los dos autores. Ciertamente las comunidades del siglo XXI no conservan más estas características en su forma original, pero son indicios de búsqueda de cambio de los padrones de la sociedad inhumana, desigual y segregada que se produjo. El análisis de Bauman se refiere a la preocupación con la libertad y seguridad, y se expresa como sigue:

Entre tanto, a cambio de la seguridad prometida, la vida en comunidad nos parece privar de la libertad, el derecho a ser nosotros mismos. Seguridad y libertad son dos valores

igualmente preciosos, que pueden ser equilibrados, pero es poco probable que sean plenamente conciliados. La tensión entre ellos - y entre la comunidad e individualidad es poco probable que se deshagan. (Bauman, 2003.p.24).

Llama la atención también al hecho de que muchos conceptos son cooptados para los intereses de la clase dominante, $y$, al parecer, queda como si toda comunidad fuera igual. Justificando el objetivo de las organizaciones comunitarias como oportunidad de reivindicación, Picard (1993, p.14), refiriéndose a las comunidades en Alemania, dice:

El objetivo perseguido por la comunidad - asegurar sus bienes, su libertad y su defensa - a menudo entra en competencia con el desarrollo del Estado-Nación. Si este Estado es estable y sus instituciones legítimas, él está a la altura de negociar con las comunidades insatisfechas y convertir en intereses políticos sus reivindicaciones. $\mathrm{Si}$ el Estado es autoritario, reacciona por la represión a lo que se ve como una amenaza o insubordinación. Si es débil, se hunde en una tormenta de rivalidades entre las comunidades que lo presionan. 
Se produjeron en la sociedad moderna ideologías que llevan a las acciones humanas a ser estandarizadas, guiadas por la producción, consumo y competitividad del mercado, contradictoriamente las diferencias y distancias sociales se profundizan llevando personas a buscar soluciones que implican el retorno a las organizaciones comunitarias. Así, surgió la economía solidaria, la economía de comunión, el comercio justo y una multitud de experiencias solidarias entre ellas el turismo comunitario.

El pensador chileno Max-Neef (2005) señala que comunidad es una red de relaciones que tiene un significado profundo entre los que la componen, aunque en la sociedad existan relaciones sociales, pero muy difusas y aceleradas. En la sociedad, la variedad de redes de comunidades es elemento fundamental para su vitalidad y diversidad. En la sociedad moderna predomina un modo de vida cuyo foco elimina al hombre y pone en su lugar al capital, así estandariza, privatiza, destruye los valores y la diversidad cultural en aras de supuestos beneficios para la economía.

La comunidad es un grupo social que vive en un pequeño espacio geográfico, cuya integración de personas entre sí y de estas con el lugar crea una identidad muy fuerte que tanto los habitantes como el lugar son identificados como comunidad. Estudiar la comunidad se hace necesario para comprender los arreglos productivos de base comunitaria o el turismo comunitario. Pequeños grupos de personas con su propia manera de ser y sentir, con sus convicciones religiosas, artísticas, su pasado histórico, costumbres típicas, su "estilo" de la vida familiar y social, sus actividades productivas, problemas y necesidades, sus aspiraciones; viviendo en mismo lugar y teniendo, sobre todo, conciencia de esta vida en común, todo esto junto forma la idea de comunidad.

Las personas se convierten en miembros de la comunidad no sólo porque viven allí, sino porque participan de la vida común del lugar, integrando conjunto de elementos que pueden ser materiales, históricos, institucionales, psicológicos, emocionales y que hacen a la vida comunitaria. Con todo, la solidaridad es el elemento principal de la comunidad y en esto está la gran diferencia de la sociedad moderna, que se esfuerza por falta de reconocimiento y participación con los problemas de uno con los otros.

La comunidad y el lugar tienen el mismo significado. Lugar es concepto geográfico y comunidad se refiere a la antropología. Mostrando la importancia del lugar, Santos (2002c, p. 314) afirma que "cada lugar es, a su manera, el mundo". Es en él donde se vive; y todos son diferentes porque tienen espacio geográfico, historia, gente y cultura diferente. Comprender los elementos que singularizan los lugares y, al mismo tiempo, los elementos que lo aproximan de los demás significa encontrar significados y posibilidades. Bauman (2003) reconoce las dificultades de la vida comunitaria, en la actualidad, debido a los avances de la sociedad moderna, pero dice que es este 
el camino que se debe reencontrar. Ciertamente las comunidades en la sociedad moderna pierden la característica de las existentes en la Antigüedad, ya que las circunstancias en las que se encuentran cambiaron brutalmente, por lo que Bauman (2003, p.9) habla de la comunidad como un paraíso perdido o a ser encontrado.

Comunidad es una de esas palabras que transmiten una sensación: es bueno "pertenecer a una comunidad", "estar en comunidad". La asociamos con las imágenes de un lugar acogedor, donde podemos refugiarnos de las amenazas que nos acechan "allá afuera", y de un mundo en el que nos gustaría vivir, pero lamentablemente no existe. En otras palabras, "comunidad" es hoy un nuevo nombre para el paraíso perdido - pero un paraíso que todavía buscamos, y que esperamos encontrar.

El autor admite que "existe una tensión entre la comunidad y la individualidad". El hecho de que la comunidad de prioridad al grupo, el nuestro, el colectivo, la comprensión compartida, lo natural y lo tácito llevo a algunos a creer que ella le quita la libertad individual, y por lo tanto, "cuando la comunidad se rompe la identidad es inventada" (Young, 1999; Hobsbawm, 1994; Bauman, 2003).

Téngase en cuenta que individualidad es diferente a individualismo. Este es la actitud egocéntrica, personal y aquello que es la esencia de cada uno de nosotros. No se puede deshacer la individualidad humana, ni en comunidad ella precisa ser negada. En la vida comunitaria lo que es combatido es el individualismo. Los miembros de una comunidad entienden que la felicidad de cada individuo depende de la felicidad de los demás, por lo tanto, la propia individualidad es pensada colectivamente. Este sentimiento negado en la vida societaria, a veces es confundido con pérdida de libertad, porque la sociedad moderna lleva la mayoría de las personas a aislarse y no querer ser molestados. Pocos se complacen en ayudar a involucrarse en la búsqueda de soluciones a los problemas de los demás.

La existencia societaria requiere la negación de la comunidad, pues admite que esta hace perder libertad, que pensar colectivamente significa negar la libertad del individuo y, por lo tanto, en sociedad, vale el individualismo. La modernidad que aproximó lugares y distancias de las relaciones humanas, llevando algunos a vivir más la realidad virtual que la real, cargando pen drives, MP3 / 4 players, están ocupados todo el tiempo en las computadoras, reduciendo los contactos personales que se han convertido en virtuales y en ciberespacios, llevando a Bauman (2003, p.18) a afirmar que: 
El golpe mortal en la "naturalidad" del entendimiento comunitario fue deshecho por el advenimiento de la informática: la emancipación del flujo de información proveniente del transporte de los cuerpos. Desde el momento en que la información pasa a viajar independientemente de sus portadores, y en una velocidad mucho más allá de las capacidades de los medios más avanzados del transporte (...) la frontera entre el "adentro" y el "afuera", no puede ser más establecida y mucho menos mantenida.

Primero, la comunidad se transformó en algo abstracto, paraíso soñado, fruto de la "imaginación humana", y "no que se trate de un paraíso que habitemos, y que no está a nuestro alcance", dice Bauman. Más tarde, en medio de las contradicciones y conflictos capitalistas, las comunidades resisten, se mantiene y hasta emergen como las experiencias aquí presentadas, pasan a ser comunidades históricas de espacios vividos duramente, ya que, están en conflicto con las ideologías de la sociedad burguesa, y sirve de referencia y estrategia de cambios para la sociedad capitalista, al medio de muchas contradicciones. Afirma Hobsbawm (apud Bauman, 2003, p.20) que la palabra comunidad "nunca fue usada de manera más indiscriminada y vacía que en las últimas décadas en que las comunidades en el sentido sociológico pasaron a ser difíciles de encontrar en la vida real". Por lo tanto, apelar para la comunidad se tornó moda, se utiliza para definir agrupamientos los más variados posibles, con diferentes objetivos, ya sean profesionales y mirando el lucro, o amigos de Orkut, a menudo alejándose del significado real y de su contenido original.

En este estudio, comunidad se refiere a lugares y grupos que tienen valores de la vida en común, que buscan soluciones para los problemas de la vida cotidiana de manera colectiva, que se preocupan de la convivencia humana más que de la acumulación, que resisten al cambio del consumismo burgués, que guardan valores tradicionales sin la preocupación de ser etiquetado como viejo y anticuado. Son comunidades que cuestionan el modelo de sociedad, de ahí son considerados grupos de resistencia. Con esto, no quiere decir que se haya eliminado los conflictos de lucha de clase, o que todos los grupos sean homogéneos. Incluso en una pequeña comunidad hay conflictos y resistencias.

\section{El turismo descubre la economía solidaria}

La sociedad brasileña se inspiró en el modo de vida urbana, industrial, se realineo rápidamente a la globalización del capital, lo que hizo concentrar riqueza en manos de pocos, lo que resulta en consecuencias negativas para los estratos sociales pobres como el desempleo, el aumento de la pobreza y de la violencia. Este modelo permite a unos pocos individuos y grupos el acceso a bienes y servicios esenciales, para disfrutar los recursos ofrecidos en el mercado, esenciales para satisfacer las necesidades ampliadas por el consumo, o acceso a la seguridad, a la justicia y a la vida política, negando para muchos otros otras oportunidades. En el caso brasileño, la mayoría son excluidos de 
tal acceso, de esta participación y de este derecho. La intensificación de este proceso viene instigando, por parte de los que sufren los choques o contrastes producidos por esta dinámica, la búsqueda de caminos que puedan mitigar la llamada exclusión social. Hizo surgir, así, la economía solidaria o economía alternativa que se contraponen al modelo económico dominante, que no cumple con las necesidades humanas de la mayoría.

Pensar en economía solidaria significa concebir un proyecto revolucionario que pueda subvertir el modelo económico vigente, para empezar. Lo que se viene llamando economía solidaria no consiste en un modo definido y único de organizar las unidades económicas, sino un proceso multifacético en el cual se puede incorporar la solidaridad y la búsqueda de un modelo justo. La filosofía que anima y dirige esta visión económica es llamada por algunos estudiosos como desarrollo a escala humana, por eliminar el foco en el capital y centrarse en las personas.

Razeto dice (1998, p.4) que se tiende a suponer que la solidaridad debe realizarse sólo después que la economía haya cumplido su tarea y tenga completado su ciclo. Que el tiempo de la economía viene primero, el tiempo para que los bienes y servicios sean producidos y una vez realizada la producción seria el momento de la solidaridad para compartir y ayudar aquellos que quedaron en desventaja, o sin trabajo, estando aparentemente excluidos. La solidaridad comenzaría sólo entonces cuando la economía hubiese terminado la tarea y la función específica. Seria puesta en práctica con los resultados - productos y servicios - de la actividad económica, pero la actividad económica en sí no sería solidaria. Lo que Razeto propone es exactamente lo opuesto, es decir, que la solidaridad sea introducida en la propia economía y que opere en las distintas etapas del proceso económico, en la producción, distribución y consumo.

Lo que la economía solidaria propone, sin embargo, es el replanteamiento de estas actividades económicas de forma que la economía sea media para el desarrollo integral de las personas. Núñez dice $(1998$, p. 1) que la gran diferencia está en el hecho de que en la economía solidaria no es necesario esperar por la toma del poder político para hacer que sucedan las cosas - ella misma es parte de la toma del poder político, ella misma es parte de la revolución, de la transición y de la construcción de modelo de sociedad justa. Se trata de revolución social de carácter local o municipal donde los grupos y comunidades que se organizan pasan a comprender que la gran revolución es la creación de una mentalidad de colaboración, de asociación. En el mundo donde imperan relaciones de competencia y de dominio, redirigir a las relaciones asociativas, la cooperación y la solidaridad significa verdadera revolución, es derrocar el orden capitalista, dicen los defensores de la economía solidaria. 
Los habitantes de pequeñas ciudades, aldeas, barrios y comunidades, cuando asumen esta lógica, pasan a considerarse sujetos capaces de interferir en la realidad socioeconómica, adquieren un papel importante tanto en la vida política como en la vida económica, social y cultural. Se organizan en asociaciones, en grupos actuantes, formando movimientos socio-políticos y van en búsqueda de soluciones a los problemas locales relacionados con la falta de trabajo, de residencias, de escuelas, en defensa del medio ambiente, a la cultura local, la mejora de las condiciones de vida de las familias locales, no de forma individualista, pero solidaria. Promueven políticas para resolver problemas y así surgen las políticas alternativas, entre ellas las del turismo. Esto es lo que realmente distingue a la búsqueda de soluciones de forma colectiva o solidaria.

La economía solidaria ganó impulso en Brasil y renueva la discusión sobre la organización comunitaria frente a la crisis del trabajo y del movimiento sindical y este debate no se ha restringido a grupos "periféricos", paso a interesar al mundo académico y organizaciones no gubernamentales. Se ampliaron iniciativas solidarias y surgió la figura del líder comunitario que paso a ser respetado, aunque muchos de ellos sean cooptados por el modelo hegemónico. Muchos grupos están dispersos en las afueras de las ciudades, en el espacio rural y en las comunidades en los espacios costeros, en los centros receptores de turismo de países ricos y pobres.

En los proyectos comunitarios, la participación consciente de los implicados es responsable del éxito de muchos emprendimientos. Las personas participan de manera efectiva en el grupo, se comprometen y hacen que suceda lo que va siendo pensado de forma colectiva. Las comunidades crecen a la medida que encuentran mecanismos para desarrollar acciones que efectúen el crecimiento del grupo, mayor poder adquisitivo y del nivel de bienestar local. Los emprendimientos solidarios son dirigidos por las comunidades en beneficio del colectivo, puede ser campo, bodega, escuela, posada o micro empresa.

La economía solidaria para Vainer(2000,p.6) está tratando de juntar cosas que se repelen y se oponen - economía y solidaridad. La sociedad donde domina la economía es el mundo de la competencia,laguerradetodoscontratodos. Esenestemundoenquevivimos.Lacompetencia es antisocial porque implica la negación del otro, dice el biólogo Chileno Maturana, como dice Boff (1999, p.111). Pensar en la solidaridad capitalista puede parecer contradictorio.

Los espacios de solidaridad se rigen por otros fines, valores y prácticas, de ahí, porque la economía solidaria es ajena al pensamiento y la práctica política neoliberal, inspirada en la crítica de la economía política clásica y en la busca de alternativas al capitalismo. Se vuelve difícil construir proyecto de solidaridad social en los marcos de la economía global, pero viene siendo posible en la escala local, 
municipal, en pequeños emprendimientos. De ahí la importancia de la política y de la lucha política en el ámbito local. La comprensión de Vainer (2000, p. 10) es que:

La expresión economía solidaria es estrictamente ideológica, difunde la creencia en la posibilidad de que la solidaridad pueda desarrollarse de forma amplia sobre la égida del capital; ya los términos: cooperativa y cooperativismo son menos ambiciosos y abarcadores, evocan una forma específica de organización de la producción y / o de la propiedad que, en algunas circunstancias y por períodos determinados, puede ser, y ha sido experimentado con ganancias materiales y simbólicos, por grupos de productores directos, incluso bajo el capitalismo.

El hecho es que el Banco Mundial, el Banco Interamericano de Desarrolloy otros organismos multilaterales, nacionales, así como algunas Organizaciones No Gubernamentales, universidades, creen en la idea de la economía solidaria y en el desarrollo local como alternativa para las periferias. Vainer pregunta si ¿La economía solidaria es el control político de los pobres o utopía experimental? Si fuera estrategia ideológica y política, en el mejor de los casos, pretende compensar la miseria engendrada por el desarrollo del capitalismo y que, casi siempre, termina produciendo sólo unos pocos mecanismos de control político de las poblaciones pobres, en el borde de la desesperación. Por lo tanto, son ideas cuestionables.

El cooperativismo para Vainer puede, en determinadas circunstancias, proporcionar experiencias, aunque limitadas en el espacio, de aquello que podría ser otra manera de producir y vivir. Es por eso que el analista habla de la utopía experimental. El término es ambiguo y contradictorio: por un lado, porque utopía es algo que no existe, es apenas sueño, por otro lado, porque al ser experimental, es algo que existe y que se experimenta. Menciona que la vida diferente muestra cómo el mundo podría ser diferente. Esto puede ser importante, porque es elemento fundamental para luchar contra la desesperanza.

La elaboración práctica y teórica de la economía solidaria tiene su origen en los movimientos cooperativos de la autogestión. Durante muchas décadas, estos movimientos han llevado a cabo los principales procesos de construcción de formas económicas alternativas, sociales y humanistas buscando respuestas a la crisis económico-social contemporánea y la transformación económica-política.

La Economía Solidaria es economía alternativa, entendida por Nunes (2006) como: "Economía de los sectores populares, economía de la dádiva, economía social, economía laboral, humano-economía, economía feminista", entre otros nombres. Se trata de una forma diferenciada de producir, enfrentando las contradicciones de la economía hegemónica. Mientras las empresas formales miran acumular el máximo beneficio 
de sus inversiones, las empresas solidarias buscan distribuir lo producido, alcanzar las condiciones para la supervivencia de grupos, preocupándose en especial, con los valores humanos, culturales y ambientales. La literatura actual sobre la economía solidaria afirma el carácter alternativo de las experiencias populares de auto-gestión y cooperación económica: dada la rotura que introducen en las relaciones de producción capitalistas, ellas representarían el surgimiento de la nueva forma de organización del trabajo y de las actividades económicas en general, garante Geiger (1994).

La economía solidaria, de acuerdo con Oliveira (2006, p.5), es una alternativa económica generadora de ingreso, compatibilizadora de los medios de producción - producción, productores y consumidores ("prosumidores"2", ) de manera equitativa. Muestra este estudio que:

En las organizaciones de economía social la propiedad de los medios de producción y la distribución de los excedentes se controlan y distribuyen entre los productores y productoras asociadas. En este contexto, la organización de las actividades productivas es definida de forma democrática y participativa, prevaleciendo la autogestión y la cooperación solidaria, y no la heterogestión y la división jerárquica del trabajo que caracterizan a las empresas capitalistas.

Es la forma de producción que desafía a la lógica del desarrollo capitalista, y, por lo tanto, las relaciones sociales de producción desarrolladas en los emprendimientos económicos solidarios, las divisiones, distribuciones no se dan necesariamente en la forma de salarios, pero de permuta, intercambios, trabajo en conjunto. A diferencia de la economía capitalista, centrada en los intereses de la acumulación de capital, de relaciones de competencia para beneficios individuales, la economía social se organiza a partir de relaciones de amistad, se sustenta en el compañerismo, favoreciendo las relaciones sociales de reciprocidad y adopta formas comunitarias de producir y distribuir.

Las experiencias comunitarias, de acuerdo con Geiger (2004), parecen similares a las de la economía campesina, o con el trabajo de las antiguas comunidades. Aunque, también aquí, las formas jurídicas y los grados de innovación en el contenido de las relaciones sean variables y sujetas a la reversión, las prácticas de autogestión y cooperación dan a esos emprendimientos naturaleza singular, pues modifican el principio y la finalidad de la extracción del trabajo excedente. Aquellas prácticas se caracterizan por:

2 Termino creado por Alvin Toffler en el libro "A Terceira Onda", refiriendose a personas que son al mismo tiempo consumidoras y productoras de bienes y servicios. 
- Funcionar basado en la propiedad social de los medios de producción, prohibiendo la apropiación individual de estos medios o su alienación particular;

- El control del emprendimiento y el poder de decisión pertenecen a la comunidad de los trabajadores, en régimen de igualdad de derechos;

- La gestión del emprendimiento estaba vinculada a la comunidad de trabajo, que organiza el proceso de producción, operaba las estrategias económicas y disponía sobre el destino de los excedentes producidos (Verano, 2001 GEIGER, 1999).

- Había unidad entre la propiedad y el uso de los medios de producción.

Tambiénsepuededefinireconomíasolidariaenelcontextodelasocio-economíasolidariaque identificaelobjetivomayordelaactividadeconómicayañadeeladjetivoapartirdelanecesidad que sienten de identificar el calor central que identifica el concepto e informa su práctica.

Tiene el mismo sentido la propuesta de la "humano economía" hecha por el economista checo Eugen Loebl (1978), en cuanto economía al servicio del humano. Economía Solidaria es la forma simplificada de referencia a la socio economía de solidaridad. Razeto (1985), uno de los autores de América Latina que utiliza esta expresión, le da fuerte contenido ético, en referencia a la frugalidad-a la organización racional del consumo en el tiempo, generosidad - a la donación de los activos excedentes, cooperación - a la libre asociación para trabajar y una distribución justa, crecimiento - bienestar colectivo y calidad de vida individual.

A partir de estos conceptos, Sampaio (2005) muestra la posibilidad de una nueva metodología de interorganización, es decir, que requiere gobernanza, se propone llamar de Arreglo Socio productivo de Base Comunitaria (APLBC). Se trata de una red de esfuerzos socio productivo e institucional, calificados como participativos y asociativos, donde predomina el reconocimiento del territorio y se da valor al conocimiento tradicionalcomunitario. Se tiene como reto superar las barreras de la racionalidad económica meramente utilitarista e incorporar los aspectos ecológicos, económicos y sociales cuando se piensa en el desarrollo de una comunidad. Se entiende que la comunidad es un tema transversal a la cuestión de la territorialidad, como es el tema de género y de la pobreza, esto es: un problema mundial, mientras es evidente la importancia de la acción territorial. Así es como este pensador ve las organizaciones comunitarias en Brasil y en Chile. 
La Economía Solidaria ha atraído la atención mundial, y tuvo un gran protagonismo en 2006, cuandoeleconomistabengalíMuhammadYunus, conocidocomoel"banquerodelospobres", ganó el Premio Nobel de la Paz por haber creado una red de micro crédito para los pobres, ayudandoamillonesdepersonasasalirdelacondicióndepobrezaensupaísnatal,Bangladesh.

En Brasil, algunos municipios y Estados se destacan con políticas públicas innovadoras en el campo del socio-economía solidaria. En el ámbito federal, el gobierno de Lula, desde el año 2003, creó la Secretaria Nacional de Economía Solidaria - SENAES, bajo la dirección del profesor Paul Singer, reconocido por su papel en las incubadoras tecnológicas de la Universidad de Sao Paulo - USP, por innúmeras inversiones como gestor público y por su destacada actuación nacional como economista. La práctica solidaria sucede a partir de la movilización de grupos, formalizando asociaciones, cooperativas y otras asociaciones y sigue la lógica de la autogestión.

Oliveira (2006) cree que la autogestión y la cooperación solidaria constituyen la síntesis de la dimensión conceptual de la economía solidaria, ya que incluye tanto la producción como la distribución del excedente. Los principios que expresan el significado de la Economía Solidaria también sugieren procesos educativos de naturaleza técnica, política y cultural. Según el autor, los atributos que caracterizan a los emprendimientos solidarios son: autogestión, democracia directa, participación efectiva, acciones educativas, cooperación solidaria y distribución equitativa. Se puede agregar otros valores y atributos a las acciones para preservar el ambiente natural, participación de los movimientos sociales, inter-relaciones solidarias de comercio y difusión de las prácticas de solidaridad para estimular la creación de otros emprendimientos.

Melo (2006), al tratar de las iniciativas solidarias, recurre a Mance (1999) que sugiere clasificar en consumo solidario o ético, comercio solidario o justo, finanzas solidarias, clubes de intercambio, bancos del tiempo y empresas de autogestión. Para poner en práctica la economía solidaria es importante entender la Red de Intercambio Solidaria y la moneda social, herramientas indispensables para la eficacia del proceso. Dice Raizeiro y Gabriela (2006, p.16) que "red de intercambio o club de intercambio es una organización que promueve el intercambio de bienes y servicios entre personas, donde se favorezcan los valores humanos y sociales sobre la especulación y las condiciones materiales".

Los intercambios solidarios se llevan a cabo a partir de la formación de grupos, lo que de alguna manera contradice la lógica del capital. Lo que importa no es el lucro, sino la auto-sostenibilidad económica de supervivencia de la comunidad, que se une y a partir de ahí produce, consume colectivamente, busca la participación de estos intercambios, promoviendo el desarrollo local. La producción del excedente 
se invierte en nuevas producciones locales para la propia generación de trabajo e ingreso. Para la aplicación de estos cambios es utilizada la moneda social.

La moneda social no es un sistema alternativo sino complementario a la economía. Ella es producida, distribuida y controlada por sus usuarios. Por eso, el valor de ella no está en ella propia, pero en el trabajo que puede hacer para producir bienes, servicios, conocimiento. Esta moneda no tiene valor hasta que se empiece a cambiar el producto por producto, servicio por servicio, producto por servicio o servicio por producto.

(RAIZEIRO y Gabriela, 2006, p. 10).

De este modo, la economía solidaria proporciona una nueva forma de establecer relaciones, las más diversas, ya sean en la producción, el consumo, la autoestima de las personas y en el espacio urbano. Es visible la organización del entrelazado urbano, la formación de nuevas redes, construcción de activos fijos y establecimiento de flujos que pasan a tener potencial de auto-gestión en el local. La Economía Solidaria despierta, en los grupos asociados por la lógica alternativa de producir, la elevación de la autoestima que les lleva a buscar asociarse con organizaciones no gubernamentales, universidades, instituciones públicas y privadas que aportan conocimientos y tecnologías innovadoras y modernas. Por lo tanto, planean acciones, que se convierten independientes y constructores de identidad territorial que modifica la organización territorial de las ciudades, barrios o comunidades.

La economía solidaria se basa en la búsqueda de la satisfacción de las necesidades humanas básicas, en la generación de niveles crecientes de la independencia de los individuos, en la articulación orgánica de los seres humanos con la naturaleza, con la tecnología, de modo que pueda integrarse en los procesos globales, respetando los valores y los comportamientos locales. Se vuelve para el suplemento de las necesidades humanas, se preocupa en tornar las personas independientes y capacitadas para utilizar la tecnología como forma de oportunidades el trabajo. Se centra en el desarrollo de los individuos como personas y como grupo, formando y orientando para convertirse en protagonistas de las transformaciones locales.

Por la participación comienzan a luchar para la construcción de un nuevo orden social, entendiendo que el orden social existente puede ser cambiado, ya que no es natural, por lo tanto, está sujeto a cambios. La participación no es sólo una estrategia política en determinadas ocasiones, sino una lucha constante de conquista de los derechos ganados y no otorgados. Participar pasa a ser un acto de libre elección, de libertad, decisión de cada socio y residente. Así, cuando alguien decide participar, moviliza su voluntad para actuar en dirección de lo que se define como objetivo y para a sentirse responsable. Cuando esta comprensión es colectiva moviliza grupos sociales capaces de cambiar la realidad. Es esto lo que se presencia en las pequeñas 
experiencias de economía comunitaria esparcidas por todo Brasil. La participación es espacio de educación política, donde es vivenciada y construida la ciudadanía. El sentido comunitario, la participación e integración de las comunidades ayudan en la promoción del turismo comunitario, promovidos por residentes y emprendedores locales.

Hay, con todo, discusión sobre las contradicciones inherentes a las actividades capitalistas que se extienden a las actividades turísticas, o sea, al generar ingresos y oportunidades de empleo, pone de manifiesto problemas socio-ambientales (degradación de las playas, especulación inmobiliaria, desmantelamiento de las dunas, contaminación de los recursos hídricos, terraplenes de los estanques y humedales, descaracterización cultural, explotación sexual de menores, desmantelamiento de las actividades tradicionales y de subsistencia de la población local), lo que revela su lado depredador así como las actividades capitalistas.

La concentración espacial de las instalaciones turísticas y por consecuencia de las inversiones públicas aumenta la desigualdad socio-espacial de procesos históricos, constituyendo problemas más visibles en las áreas urbanas, especialmente en las metrópolis del noreste. Estos son hechos considerados por muchos como factores de exclusión social, que no deben ser negados, pero también no deben ser generalizados, porque hay otras maneras de explotación del turismo no tan agresivos y de alguna manera, hasta inclusive positivamente. Se registran con mayor frecuencia algunas prácticas exitosas de actividades turísticas, con características más populares, centradas en el desarrollo social, con distribución de riqueza. Ellas pueden aparecer con diferentes nombres, tales como "turismo comunitario", "turismo de base local", experiencia de "economía solidaria", "turismo alternativo", "turismo solidario", entre otros nombres. Sin embargo, lo importante de estos experimentos es la visión de posibilidades de aprendizaje, de comunicación e inclusión de más personas y más comunidades en las acciones positivas que el turismo puede dinamizar.

Reconociendo las limitaciones del mercado y el aumento de la competencia, pequeños emprendimientos prestan atención a la economía menos mercadológica, inteligible, creando nuevos modelos de negocios que surgen de la creatividad, imaginaciones e innovación constante. Buscan economía creativa para salir de la competición y acumulación inhumana y tornarla solidaria con la participación de mercados en productos y servicios locales, y, sobre todo, con modelos de negocios y gestiones que atiendan a los excluidos del mercado formal. Surgen economías creativas que cobran cambios en el modo de producción concentrado, estandarizado y elitista. En el proceso de transición entre la economía capitalista para la solidaria todavía se observa la división de clase que tiende a unificarse en torno a la clase trabajadora. 


\section{Arreglos productivos del turismo comunitario}

Políticas son acciones que tratan de la convivencia entre personas o diferentes grupos, por eso se refiere a las relaciones que implican cuestiones de poder y organización de actividades entre grupos. Remite a los negocios públicos, privados y de intereses de la sociedad. Sujetos sociales participan de variadas actividades políticas utilizando poderes de forma diferentes, destacándose: el sector privado, el Estado y la sociedad civil organizada. El primer representado por las empresas que, en la mayoría de los casos, dominan las relaciones sociales, por contar con el poder económico. El Estado está en consonancia a los imperativos del mercado, utilizando las estructuras de poder dominante. La sociedad civil enfrenta y comparte este proceso hegemónico de forma subordinada, teniendo siempre menos poder de decisión, a pesar de ejercer presión política en determinados momentos. El análisis de estas políticas condujo a Santos (1988a, p.17) a mostrar que el crecimiento económico está asociado al "poder político, la cultura de masa, la cientifización de la burocracia, la centralización de las decisiones y la información, que provoca las desigualdades entre países, regiones y entre las clases sociales, así como aumenta la opresión y la desintegración del individuo".

En el turismo, tanto las políticas públicas como las privadas, ha incidido de forma intensiva en la costa, haciendo emerger a las llamadas políticas alternativas que parten de las comunidades, de los pequeños emprendimientos, vinculados a la economía creativa. La revalorización de la costa del nordeste para el ocio y el turismo, por la reestructuración capitalista, amplió la disputa de este espacio para nuevos usos e hizo de él la principal mercadería inmobiliaria. Ocurrió la transformación en la costa del nordeste segregando y expropiando poblaciones nativas o tradicionales de cara a los reacomodos necesarios para la ocupación turística, que se apropia de los mejores lugares, aquellos considerados bellos y atractivos. El turismo fue instalado en estas localidades, constituyendo núcleos receptivos de turismo para donde siguen flujos turísticos de las agencias de viajes, dirigidos por guías turísticos.

En el nordeste, especialmente en Ceará, este hecho ocurrió de manera arbitraria, centrado bajo el mando de intereses externos. Por ejemplo, en Jericoacoara y en Canoa Quebrada, los territorios turísticos de masiva presencia de emprendedores extranjeros, tanto turistas como empresarios, dominando y haciendo sumergir el mercado turístico local. Las dos comunidades de pescadores, además de ser despojados de sus tierras, a los espacios los dejaron sin características por la construcción de nuevos emprendimientos, de mega-proyectos turísticos. Estos mega-proyectos dirigen la actual estructura territorial, ocupando una gran parte del suelo de los dos pueblos. Instrumentos jurídicos están en las manos de propietarios extranjeros, teniendo estas grandes facilidades jurídicas para la adquisición de inmuebles que se determinan a la construcción de hoteles, condominios 
privados, restaurantes, discotecas, bares, centros comerciales, centros de convenciones, apartamentos, donde muchos fueron construidos en áreas protegidas legalmente en la costa.

Brasil se está consolidando como nuevo mercado para el turismo, ya sea residencial o inmobiliario, que tiene a los ingleses como los principales compradores mundiales, propietarios de viviendas fuera de Inglaterra. Las adquisiciones de los europeos de propiedades para segunda residencia en el extranjero crecen cada año, lo que significa nuevas propiedades y ventas que despierta el interés del mercado inmobiliario internacional y requiere estudios e investigación, pues expropian a brasileños, pareciendo para algunos, otra forma de colonización.

Los gobiernos, generalmente, se posicionan a favor de estos emprendimientos hoteleros transnacionales y facilitan lo que sea necesario para asegurar la atracción del capital extranjero, dando la infraestructura básica de servicios urbanos relacionados con el transporte urbano, comunicaciones, abastecimiento de agua, pavimentación, alcantarillado, etc. Parten del supuesto que tales emprendimientos son motores de desarrollo. Por el contrario, se quita caracterización de comunidades pesqueras para la instalación de infraestructura para el turismo, como ha ocurrido en otros núcleos del noreste con turismo internacional, como la playa de Porto de Galinhas, en Pernambuco, la playa de Pipa, en Río Grande do Norte, playas de Troncoso, Arraial d'Judá, Grarajuba, Itacaré, Porto Seguro, Praia do Forte, en Bahía y Maragogi en Alagoas.

De todas las actividades del turismo, el hospedaje es el más impactante, por forzar a la propiedad de los espacios, es decir, producir territorios, y porque en entorno de ella gravitan los demás servicios. La oferta de hospedaje no significa sólo tener espacio para dormir, sino para jugar y consumir un montón de objetos que los turistas necesitan para salir de casa, pero sobre todo objetos inducidos por el mercado, convirtiendo a los hoteles en mini centros comerciales. El poder simbólico del turismo según Bourdier (2000) ayuda a construir los sueños de los turistas, ya que opera de forma silenciosa, haciendo cómplices aquellos que a él se someten.

Los resorts son enormes complejos hoteleros, auténticos espacios arquitectónicos que utilizan mucho espacio, porque entienden el hospedaje en el sentido pleno, maneras de proporcionar placer a los huéspedes. Se multiplicaron los espacios especializados para diversas situaciones, surgiendo canchas de golf, salones de belleza, spa, salones de tenis, juegos, discotecas, gimnasios, centros de convenciones, cine, tiendas, o sea una variedad de ambientes y servicios. Emergen formas sofisticadas de hospedaje, como condohotéis que ofrecen condominio en tiempo compartido, edificios, administrados por las propias cadenas hoteleras, condominios privados y casas particulares de turistas. 
Sin embargo, cuanto más se torna una estrategia de desarrollo económico, más su imagen es reducida a la dimensión de mercadotecnia. El empobrecimiento de significados para el sector puede ser percibido en los programas de gobierno, en las prácticas del llamado trade turístico, en los comportamientos de los empresarios de la cadena de producción. Las consecuencias de esta reducción son desastrosas para la actividad del turismo, que, en la esfera pública, es considerado un gran "negocio" reduciendo políticas públicas a las simples acciones de marketing, para la venta de los destinos turísticos. En el espacio privado, la cadena de producción del turismo es estructurada sobre las bases de las economías de los sectores primario y secundario. Por lo tanto, los proyectos públicos y privados para el sector turístico se construyen por los modelos mentales y bases semánticas de economicidad que transforma la tierra, lugares, viajes, sueños, imágenes en mercadería.

Los países pobres son llevados a creer en el turismo como una actividad que induce el desarrollo, lo que no ocurre, pues se sabe que el llamado desarrollo económico tiene bases en las actividades productivas sólidas, con un gran apoyo en la industrialización. Primer el lugar necesita crecer y desarrollarse para poder el turismo establecerse con éxito. La historia del turismo en las comunidades costeras ha revelado el abuso del poder económico en el proceso de especulación de la tierra para el ocio, siendo la problemática de la expropiación de la tierra uno de los factores de explotación económica de la renta de la tierra y mano de obra, habiendo provocado el proceso de organización de turismo comunitario como una actividad de defensa y reacción al turismo invasor de comunidades. El turismo comunitario surge como contraposición al llamado turismo de los resorts y de los mega-emprendimientos y como medio de prevenir que emprendedores externos dominen las comunidades. Algunas comunidades costeras golpeadas por el proceso de especulación inmobiliaria, en nombre del turismo, crean un nuevo eje de turismo - el turismo alternativo o comunitario, por lo tanto, asociado a la lucha por la propiedad de la tierra costera.

Si los grandes hoteles y resorts simbolizan la acumulación y concentración del capital en el sector turístico, las posadas o pequeños hoteles pueden simbolizar las imágenes de un turismo menos concentrado y más solidario, menos pasteurizado y más conscientes de la diversidad cultural. El turismo no sólo mapea territorios, sino que crea la territorialidad, como define destinos, ofrece excursiones, dando visibilidad al espacio que antes era "invisible". Además de la construcción de espacios simbólicos, la actividad turística teje la extensa red de pequeñas empresas que, a su vez, crea sociabilidad a las más diversas. Así, en el Noreste siguen pari passo los dos ejes del turismo: el globalizado-oligopolizado y de la base comunitaria, que en efervescencia se contraponen y se complementan.

Estos argumentos de peso apoyan la ideología del turismo y convence a las comunidades a desarrollar actividades turísticas a menudo abandonando, sobre todo, las prácticas tradicionales básicas y más sostenibles, lo que ha creado serios problemas socio- 
ambientales. Los pescadores se convierten en camareros, jardineros, guardias de seguridad, las artesanas en camareras, renunciando a las actividades tradicionales que al ser estacionales crean dificultades. El turismo, en las comunidades, ha sido una actividad de riesgo, a veces perturbadora de las actividades tradicionales y sus resultados no siempre son satisfactorios, lo que llevó Cazes $(1999$, p.80) a afirmar que:

Un cálculo detallado de las cuentas externas del turismo, teniendo en cuenta el conjunto de las entradas y salidas financieras producidas por la recepción del turismo internacional, lleva a confirmar el pensamiento pesimista de François Ascher: no es el turismo que permite el desarrollo, pero es el desarrollo general de un país que hace del

turismo rentable

Como el turismo globalizado con los mega emprendimientos llegó a los países en desarrollo sin tener en cuenta las ocupaciones anteriores, no ofreció oportunidades y beneficios a las comunidadespesqueras, puesnolasincluyóensusproyectos, creoenalgunasdeellas, reacción negativa al turismo mundial, que paso a ser visto como una amenaza a su forma de vida.

Punto crucial resultante del avance del turismo en la costa fue la decadencia y la desaparición de actividades económicas tradicionales como la pesca, por los ingresos y el laberinto de sustitución por actividades relacionadas a hoteles, posadas, restaurantes y bares. Las comunidades costeras, que siempre han vivido de la pesca, la agricultura de subsistencia, la artesanía, acaban abandonando estos trabajos tradicionales por la competencia promovida por la pesca industrial y por la pérdida de las tierras con adquisición de terrenos y desalojo de los pescadores y sus familias de la playa. Esta arbitrariedad fue realizada por actividades inmobiliarias especulativas relacionadas al ocio y turismo, es decir, para instalación de emprendimientos hoteleros, resorts, parques acuáticos, restaurantes, tiendas, entre otros emprendimientos.

La realidad relativa a la producción y el consumo en las comunidades receptoras de turismo explicita también la naturaleza contradictoria de esta actividad que, por tratarse de capitalismo, inherente a su esencia está a la contradicción como hecho notable de este modo de producir que, mientras proporciona ocio para algunos, explora el trabajo de muchos en una misma dinámica. Martins (1999, p.29) dice que "la reproducción ampliada del capital implica la reproducción ampliada de las contradicciones que su movimiento incorpora y engendra". En la medida en que los mercados se van expandiendo, se agudizan las contradicciones inherentes a la producción del espacio que es transformado en recurso especialmente para el turismo, porque el lugar e incluso las personas exóticas son transformados en atractivo turístico. El turismo, al instalarse en las comunidades costeras, ejecutando sus emprendimientos, desencadena embates cuando se provocó enfrentamientos entre los residentes y los nuevos promotores de la 
producción espacial que desencadena formas de especulación inmobiliaria con el fin de implantar sus hoteles o resorts nacionales o de cadenas internacionales. Cuando la lógica empresarial entra en conflicto con la lógica de las comunidades, cada uno defiende sus intereses, casi siempre tiene ventajas el más fuerte que tiene mayor poder de persuasión.

La expansión capitalista se impone, en las palabras de Santos (1996), con la llamada "integración perversa", mostrando diferentes formas de participación en el trabajo y la sociedad. Por lo tanto, pescadores, trabajadores, campesinos e indígenas sirven como mano de obra, temporal y barata, incluidos en la forma explotada del trabajo por el turismo, ya que esta actividad paga mal a los proveedores de servicios. Las comunidades de pescadores se vuelven parte de este proceso y acaban por ser transformadas en centros receptores de turismo. Cuanto más exótico el lugar, más atractivo para la instalación de resorts y para el marketing turístico. El turismo es una actividad que implica el consumo de los espacios con diversidad de formas de utilización de paisajes y de negocios y de la agilidad a procesos dotados de gran capacidad de organización del espacio, instalándose en comunidades. De este modo, se materializa en los lugares, fuera de ellos es pura abstracción.

Las comunidades que luchan por el desarrollo de la comunidad no desconocen la presencia del Estado y la globalización del capital, debido a que viven los conflictos de la inserción en estas realidades, cuestionando las políticas neoliberales, en especial la estatal para revertirlas a los intereses de las economías populares, con resultados más socializados.

\section{REFERENCIAS BIBLIOGRÁFICAS}

Amaral Filho, J.; Amorim, M., Rocha, A.; Moreira, M.V.; Rabelo, D., Araújo, M. R.; Scipiao, T. (2004). Núcleos produtivos e arranjos produtivos locais: casos do Ceará. Disponível em <www.ipece.ce.gov.br>, Acesso abril/2004.

Amorim, Mônica. (1998). Clusters como estratégia de desenvolvimento industrial no Ceará. In: Prêmio Novas Idéias para um .Novo Nordeste. Fortaleza: Banco do Nordeste. Ander-Egg, Ezequiel. (1980). Metodología y práctica del desarrollo de la comunidad. Buenos Aires: Lumen-Hvmanitas.

Araújo, Vera. (1998). Economia de comunhão e comportamentos sociais. In: COSTA, Rui et al. Economia de comunhão. São Paulo: Cidade Nova.

Bauman, Zygmunt. (2003). Comunidade: a busca por segurança no mundo atual. Rio de Janeiro: Zahar.

Benevides, Ireleno P. (1998). Planejamento Governamental do Turismo: Meio Ambiente Construído e Desenvolvimento no Nordeste. In Lima, L.C. Da cidade ao campo: a diversidade do saber- fazer turístico. Fortaleza, FUNECE-BNB. 
Benko, George. 2001. A recomposição dos espaços. In: Revista Internacional de Desenvolvimento Local. Vol. 1, N. 2, p. 7-12, Mar.

Bourdieu, Pierre. (2000). O Poder Simbólico. Rio de janeiro: Bertrand Brasil.

Boff, Leonardo. (1999). Saber Cuidar: Ética do Humano - Compaixão pela Terra. Petrópolis: Vozes.

Cavaco, Carminda. (1996). Turismo rural e desenvolvimento local. In: RODRIGUES, Adyr B. (org.). Geografia e turismo. Reflexões teóricas e enfoques regionais. São Paulo: Hucitec.

Casarotto, F. Nelson e Pires, H. Luis. (1999). Redes de pequenas e médias empresas e desenvolvimento local. São Paulo: Atlas.

Cazes, Georges. (1999). Turismo e subdesenvolvimento: tendências recentes. In:

Rodrigues, Adyr B. (Org.). Turismo e geografia: reflexões teóricas e enfoques regionais. São Paulo, Hucitec.

Claval, Paul. (2007). A Geografia Cultural. Florianópolis: Ed. da UFSC.

Crocco, Marco Aurélio. (2003). Metodología de identificação de Arranjos Produtivos Locais Potenciais. Belo Horizonte: CEDEPLAR.

Coriolano, Luzia Neide M. T. (Org.). (2003). O Turismo de Inclusão e o Desenvolvimento Local. Fortaleza: EDUECE.

Diegues, A. C. S. (2002). O mito moderno da natureza intocada. $3^{\circ}$ ed. São Paulo: HUCITEC.

Dolabela, F. A (2006). pergunta recorrente: e depois que aprendermos a fazer o pão?

Disponível em $<$ www.dolabela.com.br $>$ Acesso: 13/05/06.

Droulers, Martine e Milani, Carlos R. S. 2002. Desenvolvimento local e turismo em Tarrafal - Cabo Verde. Paris: UNESCO.

Eugen, Loebl. (1978). A Humanoeconomia. São Paulo: José Olympio.

Fillion, Louis Jacques. (1999). Empreendedorismo: empreendedores e proprietáriosgerentes de pequenos negócios. Revista de Administração. São Paulo.

Geiger, Pedro. Des-territorialização e espacialidade. In: SANTOS, Milton (et. all.).

Território, globalização, fragmentação. São Paulo: Hucitec, 1994.

Hobsbawm, Eric. (1994). Era dos Extremos: o breve século XX (1914-1991). São Paulo: Companhia das letras.

Mance, Euclide A. (1999). A revolução das redes: a colaboração solidária como uma alternativa pós-capitalista à globalização atual. Petrópolis: Vozes.

Martins, Sérgio. Crítica à Economia Política do Espaço. In: Damiani, Amélia Luisa; Carlos, Ana Fani Alessandri; Seabra, Odete Carvalho de Lima. O Espaço no fim do Século: a nova raridade. São Paulo: Contexto, 1999. (Coleção Novas Abordagens). Max-neef, Manfred A. Turismo como fenômeno humano. In SAMPAIO, Carlos A. Cioce. Turismo como Fenômeno Humano: princípios para pensar a socioeconomia. Santa Cruz do Sul: EDUNISC, 2005. 
Melo, Heron Albergaria. (2006). Economia solidária e a reconstituição das alternativas de sobrevivência. Disponível em: <http://wi.sei.ba.gov.br/publicacoes/publicacoes_sei/ bahia_analise/analise_dados/pdf/retros2004/heron_albergaria.pdf >, acesso em: $05 / 12 / 2006$

Nunes, Ruth Espínola Soriano de Souza. (2006). Socioeconomia solidária enquanto alternativa sistêmica. Disponível em: $<$ http://www.pacs.org.br/artigospublicacao/socioecono\%20alt\%20sistema\%20ruth\%20nov\%202003\%20por.rtf >, acesso em: 05/12/2006 Nuñez, Orlando. (1998). Os Caminhos da Revolução e a Economia Solidária. Revista Proposta. n. 75. Dez/ fev. de 1997/1998, disponível em: <www.alternex.com.br>. Oliveira, Aécio Alves. (2006). A economia solidária e o turismo. In: FUNDAÇÃO Demócrito Rocha. Turismo de inclusão. Fortaleza: FDR.

Oliveira, Francisco. (2001). Aproximações ao enigma: o que quer dizer desenvolvimento local? São Paulo: Instituto Pólis; Programa Gestão Pública e Cidadania/EAESP/ FGV.

Ortega y Gasset, José. (1973). O Homem e a gente - Inter-Comunicação Humana. Trad de, J. Carlos Lisboa. Rio de Janeiro: Ibero-Americano.

Picard, E. (1993). Le réveil Communautaire. Currier de L' UNESCO, Paris.

Piore, M.J. \& Sabel, C.F. (1984). The second industrial divide: possibilites for prosperity. New York: Basic Book.

Porter, Michel. (1993). A vantagem competitiva das nações. Rio de Janeiro: Campus. Raizeiro, Ary Gabriela, Maria. (2016). Trocas solidárias. Disponível em: $<$ http:// www.geranegocio.com.br/html/geral/microcredito/trocaed.html $>$, acesso em:

$05 / 12 / 2006$

Razeto, Luis. (1985). Economia de solidaridad y mercado democratico. Santiago de Chile: Academia de Humanismo Cristiano.

Razeto, Luís. (1998). Economia de solidariedade e organização popular. In: Gadotti, M.; Gutierrez, F. (orgs.). O Papel Central do Trabalho e a Economia de Solidariedade. Rev. Proposta. n.75. Dez/ Fev 1997/1998. <www.alternet.com.br>.

Rica, José.(2004).Sebrae: O Jovem empreendedor. In: Revista Estudos Avançados. v.18, n.51.

Sachs, Ignacy. (2006). Uma nova economia para o século XXI. In Jornal da USP. Ano 22, n.782, Nov.

Sampaio, Carlos Alberto Cioce. (2005). Turismo como fenômeno humano: princípios para se pensar a socioeconomia. Santa Cruz do Sul. EDUNISC.

Santos, Milton. (1988). Metamorfoses do espaço habitado. Ed: HUCITEC, São Paulo: lo: Hucitec. (1996). A natureza do espaço: técnica e tempo - razão e emoção. São Pau(2002). Por uma outra globalização: do pensamento único à consciência universal. $9^{\text {a }}$ ed. Rio de Janeiro: Record. 
Vainer, Carlos. (2000). Controle político dos miseráveis ou utopia experimental? In: Unitrabalho. N.10 Ano 3. Janeiro.

Verano, L. (2001). Economia solidária, uma alternativa ao neo-liberalismo. Santa Maria: Cesma Edições.

Young, Jook. (1999). The exclusive society. Londres: Sage. 